\title{
Investigating seismic properties of the NEGIS onset region using ice-drilling noise as a seismic source
}

Charlotte Schoonman ${ }^{1 *}$, Olaf Eisen ${ }^{1}$, Coen Hofstede ${ }^{1}$, Nicolas Stoll ${ }^{1}$, Steven Franke ${ }^{1}$. Emma C. Smith ${ }^{1.2}$

${ }_{1}^{1}$ Alfred Wegener Institute Helmholtz Centre for Polar and Marine Research, Bremerhaven, Germany

${ }^{2}$ now at: School of Earth and Environment, University of Leeds, Leeds, United Kingdom

Presentation Outline

1. Motivation and Aims

2. Network Layout

3b. Gliding Tremors

\section{Source}

Characterisation

3a. Core breaks

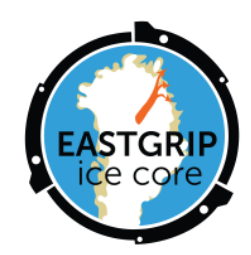

4. Conclusions and Further Work 


\section{Motivation \& Aims}

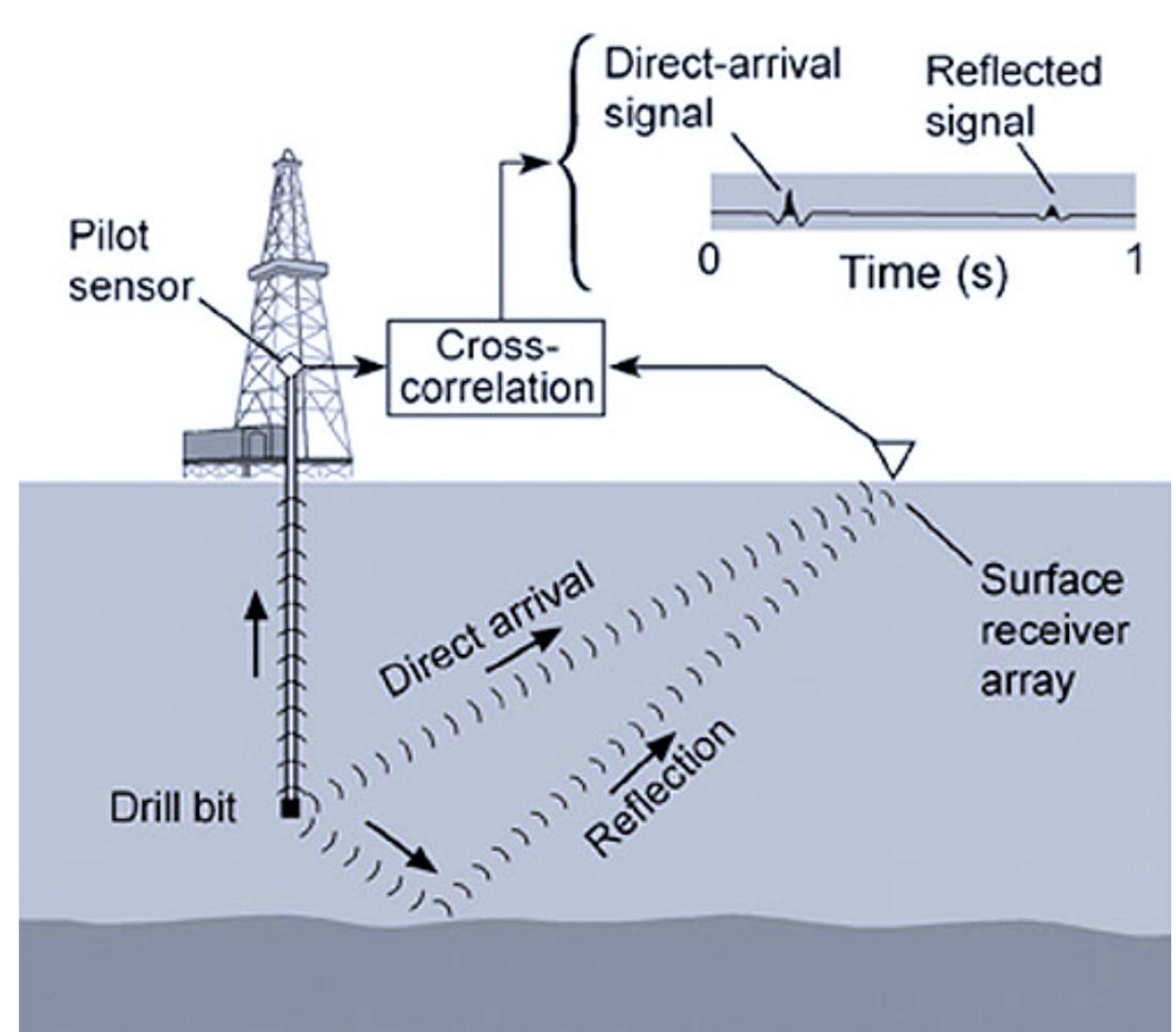

A schematic illustration of the seismics-while-drilling method (after Hardage, 2009)
Investigating the physical conditions underlying and enabling fast glacier flow is crucial to understanding the future stability of ice sheets, as well as their impact on future sea-level rise.

Seismic surveys have been widely used to measure material properties of ice and its substrate. While traditional seismic surveys rely on natural seismicity or man-made sources such as explosives, anthropogenic noise generated through ice-core drilling can also be used as a seismic source. Placing geophones around an ice-core drilling site therefore presents an exciting opportunity to complement and extend measurements from ice cores to the surrounding area.

In a seismics-while-drilling experiment, the acoustic signals generated by drilling act as seismic sources, which are recorded by a network of geophones at the surface. As the drill progresses through the ice column, the corresponding variation in seismic signals can be used to generate a vertical profile of seismic properties, including seismic velocity structure and anisotropy.

The aim of our pilot study is to test the feasibility of the seismics-while-drilling method at the EGRIP ice core drilling site, by:

- Characterising the different anthropogenic and glaciogenic signals recorded by our geophone network

- Determining first-order velocity structure using impulsive arrivals

- Identifying areas of improvement to the seismics-while-drilling setup for future experiments 


\section{Network Layout}

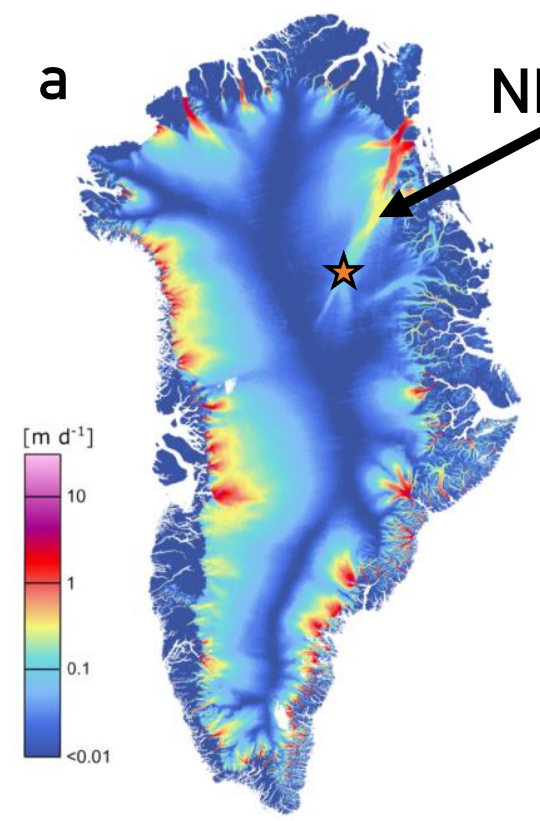

(a) Ice velocity of the Greenland Ice Sheet 20192020, (ENVEO, 2020).

Orange star marks EGRIP drilling site.

(b) Map of the EGRIP field site, showing geophone deployment in red triangles. White arrow: approx ice flow direction. Background: Sentinel-2 NIR image, captured 7/7/19

\section{Regional Context}

The East Greenland Ice Core Project (EGRIP) site is located near the onset region of the Northeast Greenland Ice Stream (NEGIS), which drains over $10 \%$ of the Greenland lce Sheet.

\section{Network Characteristics}

In the summer of 2019 , nine 3-component surface geophones were deployed at approx. 0, 300, 750, 1500 , and $3000 \mathrm{~m}$ distance from the EGRIP drill site along two lines, corresponding to the along- and cross-flow directions of the ice stream.

The network recorded 28 days at a sampling frequency of $400 \mathrm{~Hz}$. During the deployment, drilling progressed from $1920 \mathrm{~m}$ to $2110 \mathrm{~m}$ depth. 


\section{Source Characterisation}

\section{Anthropogenic (drilling-related) sources}

While drilling is in progress, two distinct types of seismic signals are observed:

1. (Semi-)continuous noise: e.g., generators

2. Impulsive events: e.g., core breaks

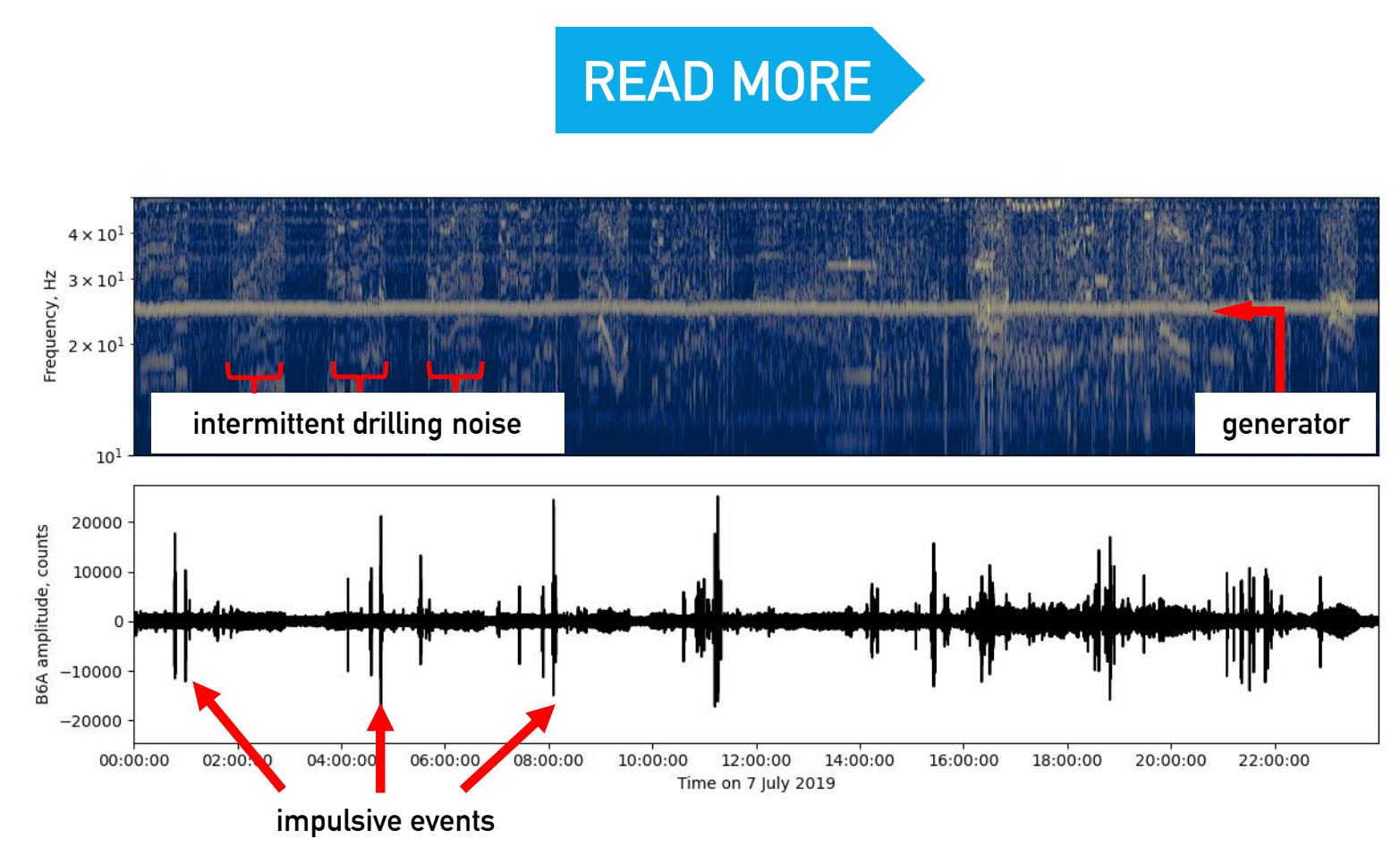

\section{$\underline{\text { Glaciogenic sources }}$}

The network also recorded a variety of glaciogenic signals, including:

1. Episodic 'gliding' tremors (basal motion)

2. Icequakes

\section{READ MORE}
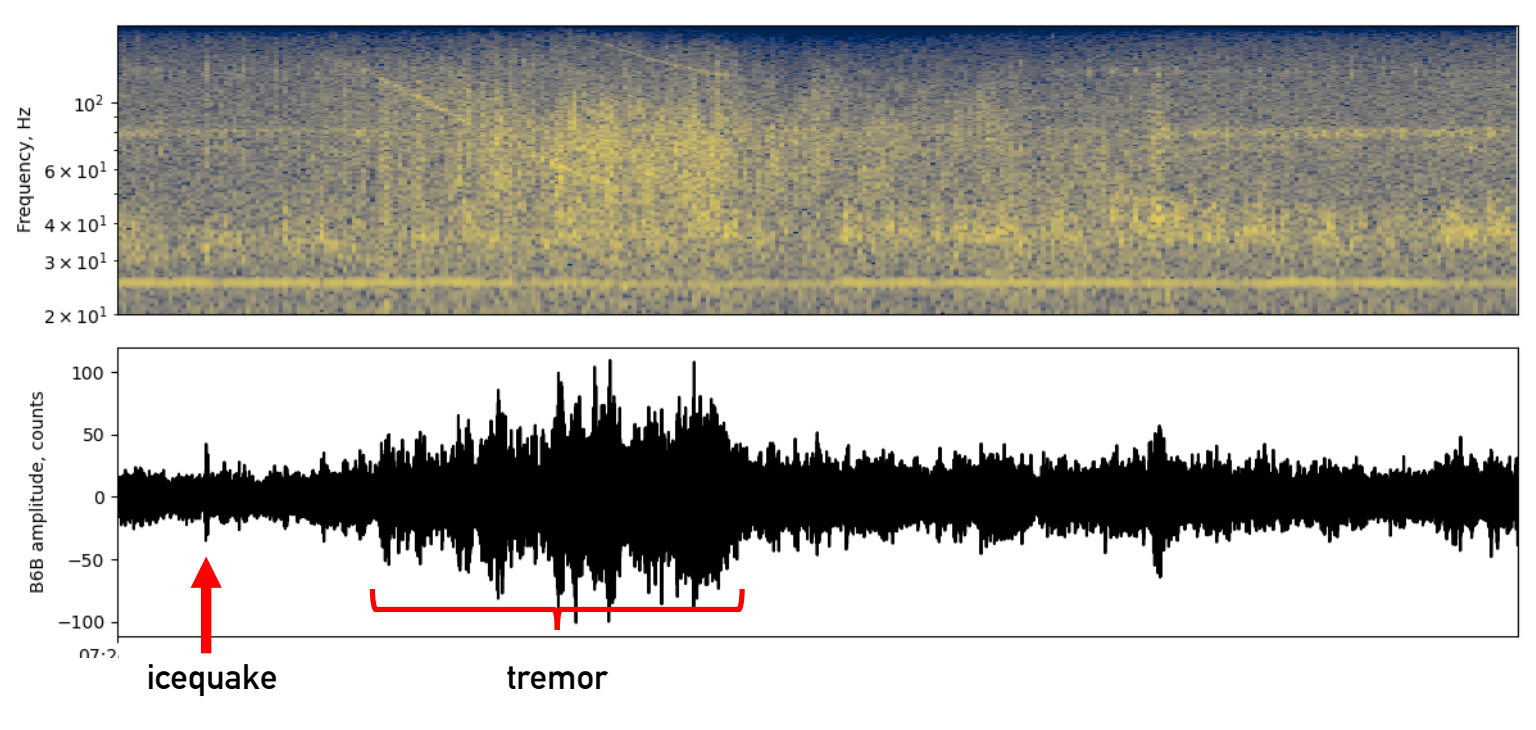


\section{3a. Impulsive Events (e.g. Core Breaks)}

The geophone network recorded many ( $>50$ per day) impulsive signals related to drilling. These events are characterised by their high frequency content (45$200 \mathrm{~Hz}$ ), decaying amplitude with increasing offset, and highly similar waveforms (cross-correlation $>0.6$ ), consistent with an invariant source location.

To further investigate these signals, we combined an STA/LTA phase picker with a template-matching algorithm to identify as many of the events as possible.

We predict approximate arrival times assuming a constant $\mathrm{P}$-wave velocity and sources located (a) at the drill-head and (b) the surface. For nearly all events, a surface source better fits the observed arrival times, suggesting the signal is actually originating from the drill tower.

The predicted arrival times also highlight an apparent difference in seismic velocity between the along- and cross-flow directions. Assuming the source is at the surface allows us to use the Herglotz-Wiechert method to estimate qP velocities and ray turning depths along each direction.

For depths of $45-60 \mathrm{~m}, \mathrm{qP}$ velocity is up to $\sim 3845 \mathrm{~ms}^{-1}$ in the cross-flow direction and up to $\sim 3815 \mathrm{~ms}^{-1}$ in the along flow direction $(1-3 \%$ faster in the cross-flow directions). Further work will refine and extend these estimates.

Right: Record section of an impulsive event related to a core break. Red bars = predicted Pwave arrival times for waves originating at drill head. Blue bars = predicted arrival times for waves originating from the drill tower at the surface.

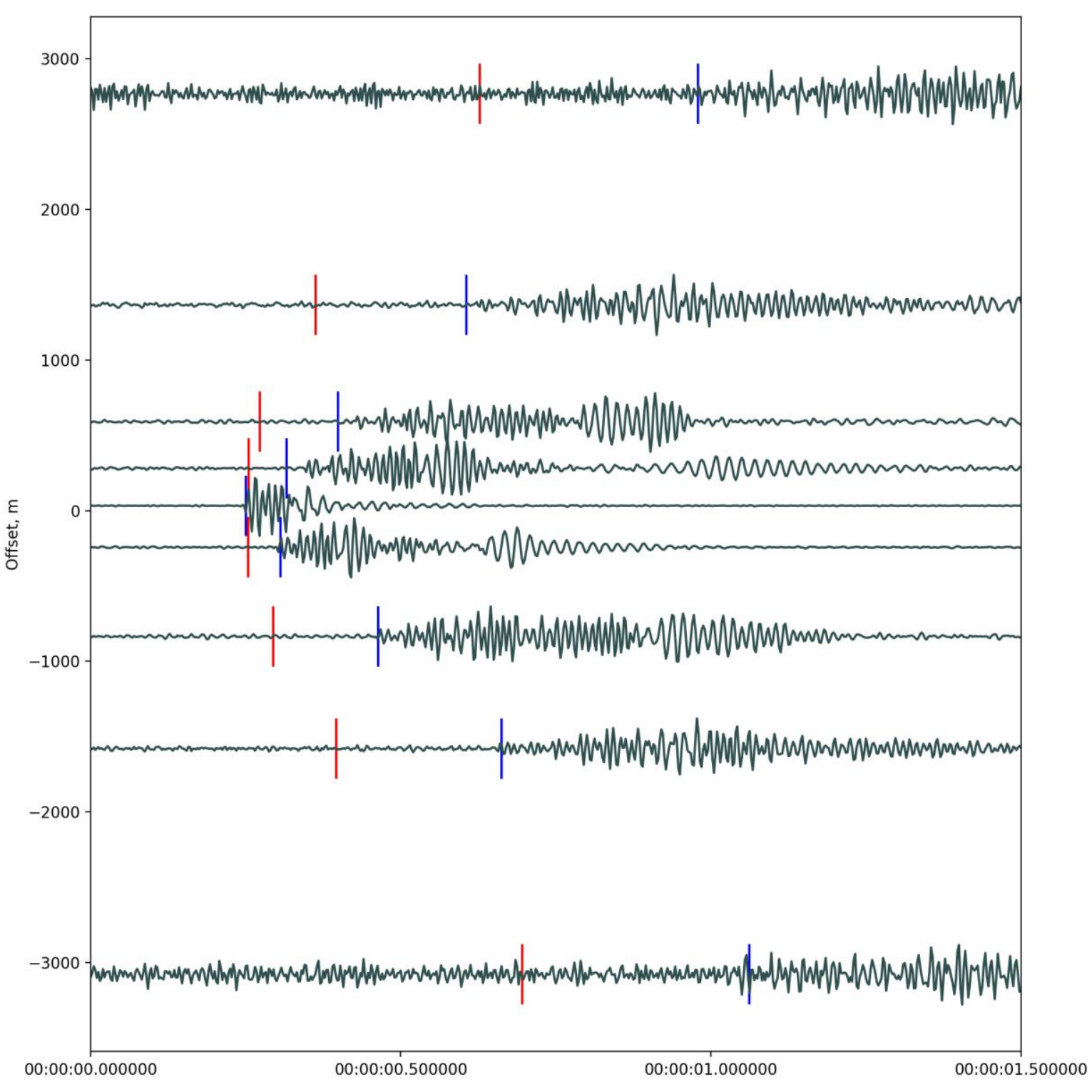




\section{3b. Gliding Tremors}

\section{HOME}

\section{Observations}

- Episodic tremors of 10-100 s in length

- Sometimes preceded by individually distinct icequakes

- Dominant frequency varies throughout time (spectral gliding)

- Observed simultaneously at all stations

- At lower offsets, tremors are obscured by anthropogenic noise

\section{Interpretation}

Similar tremors have been observed at Whillans Ice Stream (Winberry et al. 2013) and are thought to be convolved waveforms of rapidly repeating icequakes, related to stick-slip motion along the ice stream bed.

\section{Future work}

- Examine GPS records for evidence of stick-slip behaviour at times of tremor

- Model the tremor episodes to obtain physical properties of substrate (e.g. Lipovsky \& Dunham, 2016)
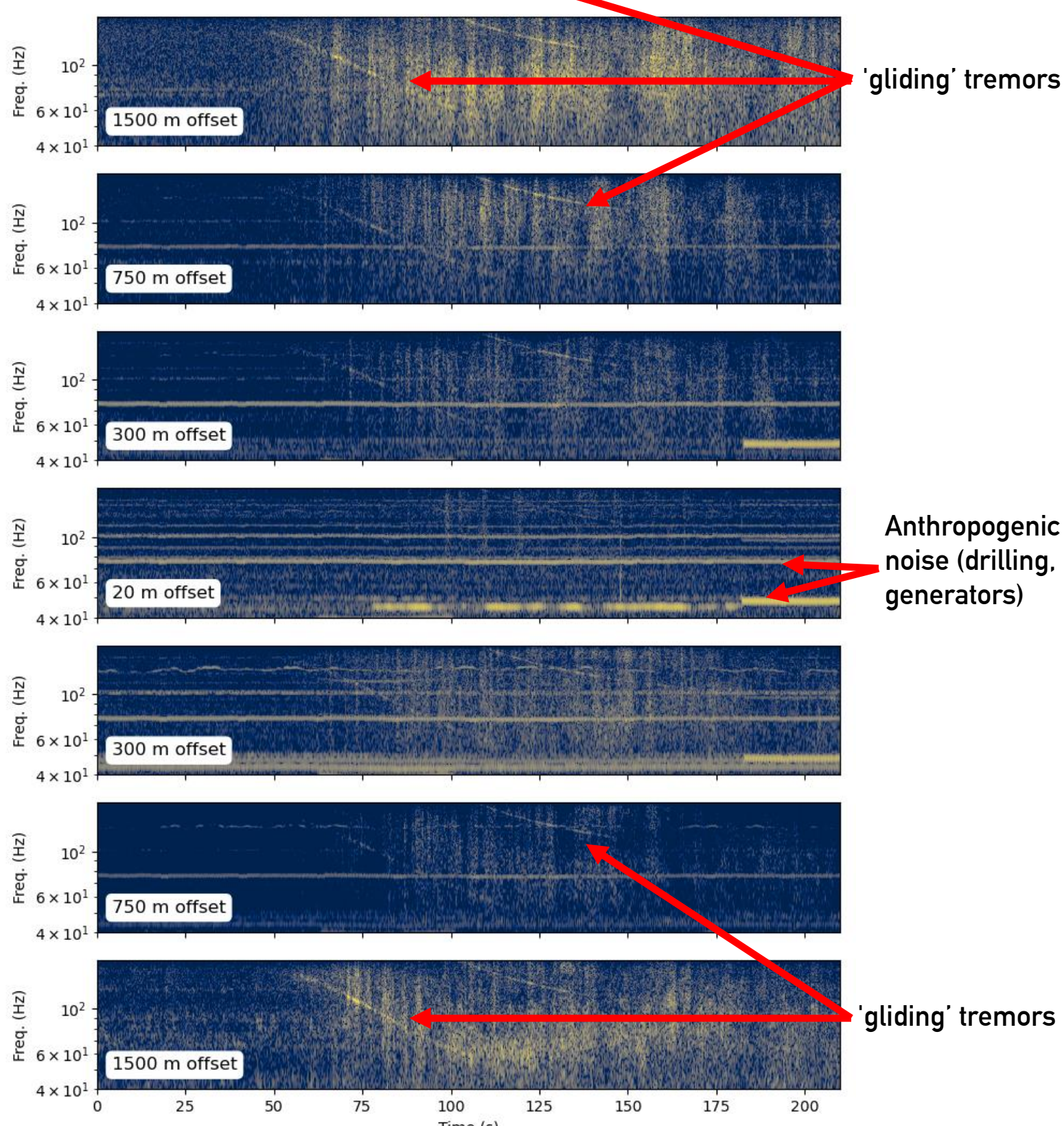


\section{Conclusions and Further Work}

\section{Conclusions}

- Seismics-while-drilling capitalises on existing sources of seismic signals at drill sites, allowing measurements from ice cores to be extended to the surrounding area

- Preliminary analysis of impulsive events propagating from the drill tower indicate anisotropy in the top $60 \mathrm{~m}$ of firn, with P-waves travelling 1-3\% faster in azimuths orthogonal to ice flow

- Besides anthropogenic noise, many glaciogenic signals (icequakes, tremors) are recorded, suggestive of stick-slip motion at EGRIP

In the future, we also hope to:

1. Apply cross-correlation to continuous drill noise to obtain detailed profiles of seismic properties

2. Model glaciogenic tremors to obtain the shear modulus of the substrate

3. Deploy a more extensive network at EGRIP to allow for more refined analysis 


\section{REFERENCES}

Hardage, B. (2009): Drill-bit seismic still has teeth, AAPG Explorer

http://www.searchanddiscovery.com/documents/2009/40411 hardage/images/hardage.

Lipovsky, B. P. and Dunham, E. M. (2016): Tremor during ice-stream stick slip. The Cryosphere, 10, 385-399, https://doi.org/10.5194/tc10-385-2016

Winberry, J. P., Anandakrishnan, S., Wiens, D. A., and Alley, R. B. (2013), Nucleation and seismic tremor associated with the glacial earthquakes of Whillans Ice Stream, Antarctica, Geophys. Res. Lett., 40, 312- 315, doi:10.1002/grl.50130

\section{ACKNOWLEDGEMENTS}

EastGRIP is directed and organized by the Centre for Ice and Climate at the Niels Bohr Institute. University of Copenhagen. It is supported by funding agencies and institutions in Denmark (A. P. Möller Foundation, University of Copenhagen), USA (US National Science Foundation, Office of Polar Programs), Germany (Alfred Wegener Institute. Helmholtz Centre for Polar and Marine Research), Japan (National Institute of Polar Research and Arctic Challenge for Sustainability). Norway (University of Bergen and Bergen Research Foundation), Switzerland (Swiss National Science Foundation), France (French Polar Institute Paul-Emile Victor, Institute for Geosciences and Environmental research) and China (Chinese Academy of Sciences and Beijing Normal University). 